\title{
No Money in Social Work - Negotiating Compensation for Social Workers
}

\author{
Nafees Alam* \\ Researcher, Yeshiva University, USA
}

Submission: August 05, 2019; Published: August 13, 2019

*Corresponding author: Nafees Alam, Professor, Researcher, Yeshiva University, USA

\begin{abstract}
The compensatory legitimacy of social work is closely tied to the societal legitimacy of the profession. Much like the trajectory of the nursing profession of old, social workers carry the burden of negotiating and advocating on behalf of themselves in achieving optimal compensation, indicative of their professional and academic accord. Accessing and interpreting organizational financials, being aware of potential dead-end promotions and alternatives to higher compensation and formulating strategies in negotiating compensation, practicing self-advocacy, are of utmost importance in this endeavor. The coalition of social workers across the nation can band together to achieve fair and just compensation for all social workers, beginning with BSW educators being mindful of the messaging around social work practice and compensation. If prospective social workers are taught to believe the fallacy of 'no money in social work', they are likely to fall short of their career earnings potential.
\end{abstract}

Keywords: Compensation; Negotiation; Self-advocacy; Nursing

\section{Labor Statistics Comparison Between Social Work and Nursing}

According to the US Bureau of Labor Statistics (2019), the median annual salary for all social workers in the United States as of May 2017 was $\$ 47,980$ ( $\$ 10,290$ more than the median annual salary for all occupations in the US economy combined), with the lowest $10 \%$ earning less than $\$ 29,560$ and the highest $10 \%$ earning more than $\$ 79,740$. In comparison, the median annual salary for all registered nurses in the Unites States was $\$ 70,000$ $(\$ 32,310$ more than the median annual salary for all occupations in the US economy combined), with the lowest $10 \%$ earning less than $\$ 48,690$ and the highest $10 \%$ earning more than $\$ 104,100$. As of 2017 , the median salary for US registered nurses was $\$ 22,020$ higher than the median salary for US social workers.

Looking back, between 2000 and 2001, the median annual salary for US social workers was $\$ 37,694$ Linsley [1], only $\$ 5,289$ less than the median annual salary for US registered nurses $(\$ 42,983)$ Spratley, et al. [2], compared to the $\$ 22,020$ difference that exists as of 2017 . This indicates a $38.6 \%$ growth in the median salary for US registered nurses during this timeframe, but only $21.4 \%$ growth in the median salary for US social workers. According to the Consumer Price Index (2019), the US inflation rate between 2001 and 2017 was $2.05 \%$ per year, meaning that prices in 2017 were $38.41 \%$ higher than they were in 2001. Nursing salaries have kept on pace with inflation over the years, while social worker salaries have not.
It would be a heavy-handed overreach to assert that social workers should be compensated similarly to registered nurses, given the differences in working conditions, education, etc. Clearly, the difference in compensation between social workers and nurses is well justified. However, median compensation being just $\$ 5,289$ apart in the early 2000's to being $\$ 22,020$ apart in 2017, with social workers now having less buying power now than they did back then, suggests that the field of social work is undervalued. Quite the opposite is true in fact, as the field is projected to grow $16 \%$ from 2016 to 2026, which is $9 \%$ higher than the projected growth for all occupations combined US Bureau of Labor Statistics $[3,4]$.

\section{Messaging in Social Work as a BSW Educator}

'There is no money in social work'... a phrase that needs no citation for it is universally accepted by social work practitioners and uniformly expressed by social work administrators. A perfect storm by which administrators have long suppressed the career earnings of practitioners through strategic messaging, much like the nursing profession of old. A message kept alive today, even by the most unlikely of messengers: veteran social workers and retirees who have found little compensation in the field themselves, fearful that learning of the compensation there is to be had in the field of social work potentially highlighting all that they have missed out on during the course of their respective careers. 


\section{Annals of Social Sciences \& Management studies}

Quite often, when a knowledgeable administrator is adamant on communicating how little compensation there is to be had in the field of social work, they are trying to low-key recruit and hire the practitioner they are speaking with. Convincing the practitioner of this "fact" allows the administrator to set the table for a low-ball offer unlikely to be challenged, much less negotiated. Acceptance of this offer by the practitioner then sets the table for years, decades, perhaps even an entire career of never getting paid what they are worth despite there being adequate funds. Consider for a moment that a practitioner settling for $\$ 40,000$-a-year being promised $\$ 50,000$-a-year after five years of employment has essentially missed out on a full year's salary during this span alone.

With prospective social workers at the BSW level generally being new to the field and impressionable, the responsibility falls upon BSW educators to be mindful of messaging around social work practice and compensation. If prospective social workers are taught to believe that there is 'no money in social work,' they are likely to find 'no money in social work.'

\section{Accessing and Interpreting Organizational Financials}

A cost-free account on Guidestar allows anyone to view and download the 990 Tax Forms for secular non-profit organizations with revenues over $\$ 200,000$ or assets over $\$ 500,000$. On Part I, Line 22 of the 990 (towards the bottom of page one), the net assets or fund balances are shown, subtracting the fiscal year's total liabilities (Line 21) from the fiscal year's total assets (Line 20 ). This is the net gains or losses for the fiscal year, meaning that this figure represents how much a nonprofit organization made or lost after expenses have been accounted for, otherwise known as an organization's net worth.

A nonprofit organization's net assets or fund balances could range a wide span, with many over $\$ 100,000,000$ and only $30 \%$ showing net-losses over three years Guidestar [5]. In the interest of accuracy, it's best for practitioners to access the 990 specifics to the organization with whom they are employed or wish to be employed. Often, they'll find that nonprofits are indeed quite profitable. Delving further into the organization's 990 (Schedule J, Part II - Officers, Directors, Key Employees, and Highest Compensated Employees) shows executive compensation, sure to raise the eyebrow of any practitioner brainwashed into subscribing to the aforementioned 'no money in social work' ideology and being asked to settle for lower compensation than they are comfortable with. It isn't unusual to find annual salaries between $\$ 500,000$ to over $\$ 1,000,000$ at the top of these lists.

Strategies for Negotiating Compensation, Practicing Self-Advocacy

It's one thing to know that there is compensation to be had in the social work profession, it's another to know how to earn that level of compensation. The first step a practitioner should take is acknowledging that social work is a legitimate profession, worthy of legitimate compensation. Some would term this as 'knowing our worth.' Much like the trajectory of the nursing profession over the last few decades, the social work profession will gain compensatory legitimacy through societal legitimacy. Not too long ago, there was 'no money in nursing.' Today, the median income for a registered nurse is $\$ 70,000$-a-year (US Bureau of Labor Statistics, 2019). Although the movement is still at infancy today, social work is beginning the move toward compensatory legitimacy by way of societal legitimacy, as referenced by the $\$ 10,286$ median annual salary growth between 2001 and 2017, with projected growth in the field of social work between 2016 and 2026 being 16\% [3,4].

The second step a practitioner should take is knowing the organization with whom they are employed or wish to be employed. This includes learning the history and mission of the organization in addition to their financials. Practitioners may be hesitant to go into interviews or meetings with the organization's 990 document in hand, as this may seem adversarial, but there's nothing wrong with bringing the organization's own report to a such a forum. If the organization has high positive net assets or fund balances, the practitioner should confidently negotiate an appropriate annual salary on their own behalf (based on local, state and federal standards for the specific position within the organization). When the company line is deployed, "there is no money in social work," simply take out the organization's 990 and point to Line 22, then to Schedule J, Part II - Officers, Directors, Key Employees, and Highest Compensated Employees.

There will be moments of discomfort during the negotiation process, but practitioners should understand that this is not a feeling exclusive to the practitioner, but to the organizational representative as well. Many times, the organizational representative themselves may not be privy to the fact that their nonprofit organization is as profitable as the 990 indicates. In defense, they may voice their discomfort by stating that the practitioner is being too aggressive in negotiating their compensation. The response by the practitioner should be simple: the aggressiveness with which they advocate on their own behalf is the same aggressiveness with which they will advocate on behalf of the organization's clients and consumers. A practitioner who is too timid to advocate aggressively on their own behalf will likely be so in advocating on others' behalf, hence value is built by demonstrating the advocacy skills possessed by the practitioner.

Organizational representatives are thoroughly trained to gain a competitive advantage Noe [6]. Reference will be made to the 'average social worker' being compensated in the same way they propose the practitioner should be compensated. The practitioner shouldn't be hesitant to ask if the organization is seeking an 'average social worker' or if the goal is to find one who performs head and shoulders beyond their peers at the position. The practitioner should make it clear that social work is a legitimate profession and, as with any and all legitimate professions, average compensation will yield average performance.

Newer practitioners with little to no experience may be met with organizational representatives reluctant to negotiate optimal compensation based on their lack of experience. These 
practitioners can use their lack of experience as a strength by stating that they haven't had the misfortune of developing bad habits through poor practice or poor leadership in past positions. A quick compliment to the organization goes a long way, simply stating that based on the practitioner's research into the organization with whom they wish to be employed, they've found no indications of poor practice or poor leadership being taught to new practitioners.

\section{Tactics Used Against Social Work Practitioners Negotiating Compensation \\ Dead-end promotions}

Negotiating compensation isn't the end of the practitioner's self-advocacy, rather the beginning. Administrators are trained to have their finger on the pulse of their organizations, and this includes anticipating and preparing for what is ahead. For example, if an administrator notices a practitioner with an undergraduate degree showing advanced performance relative to their professional capacity, with several waivers and approvals from their superior(s), the administrator may offer this practitioner a position that generally requires a graduate degree at a higher salary than what the practitioner currently makes, with the condition that they not pursue a graduate degree. This condition is like the conditions placed upon medical students and doctoral candidates expected not to take on outside employment [7].

This practitioner may see $\$ 10,000$ more per year and a promotion to a higher-ranking position with no further expectations for academic advancement as a great deal, but it is in fact a trap. The administrator and the organization are banking on the idea that the practitioner will become so accustomed to their $\$ 10,000$-a-year pay increase that they wouldn't dare leave the position or the organization for decades to come. After about five years, if the practitioner still yearns for higher compensation, the administrator could offer the practitioner their old position (and \$10,000-a-year less) while they further their education and achieve their graduate degree, knowing that this wouldn't be a deal that the practitioner would likely take because they have grown accustomed to their current salary. If the practitioner then seeks to interview with other organizations, the administrator could call their bluff, knowing that other organizations will offer compensation to the practitioner based on their undergraduate degree, not based on how the fact they've operated within a position generally requiring a graduate degree for the past five years. The practitioner is trapped in a seemingly dead-end position: they cannot advance their career earning potential since doing so would require a graduate degree (and thus a short term pay decrease) and they cannot leave the organization because they will be seen as an undergraduate degree candidate by other organizations, warranting undergraduate degree compensation. In many instances, if a promotion seems too good to be true, it usually is.

\section{Alternatives to higher compensation}

Administrators fielding requests for higher compensation from practitioners can, after conversing with their superior(s), offer alternatives to higher compensation that could appease practitioners for decades to come. Administrators in the profession of social work are no strangers to human behavior themselves, some even experts in the field. They know that emotions play a big role in everyday life for everyone, especially practitioners in an emotionally charged profession.

In lieu of a raise, administrators could first offer greater recognition for practitioner accomplishments. During daily, weekly or monthly unit meetings, administrators can praise practitioners in a public forum, showing their appreciation for the work that they do. Administrators know how much satisfaction public praise can bring to practitioners and they are banking on the idea that it is unlikely practitioners will leave their organizations for new organizations, even for higher compensation, because they'll have to make a name for themselves anew before being praised again.

If the practitioner returns to the administrator asking for higher compensation even after months of consistent public praise, the administrator can, with the approval of their superior(s), offer practitioners work from home during their documentation days. If, for example, the organization expects all practitioners to be in the office documenting their week's contacts on Fridays, the administrator can offer that the practitioner document from home every Friday (assuming remote access to documentation platforms are made available by the organization), thereby having the chance to spend more time with friends, family, spouses, children, etc. The administrator can further suggest that if the practitioner has all their documentation completed by Thursday, they're essentially enjoying a three-day-weekend after a fourday-workweek. This is yet another tactic to appease practitioners seeking higher compensation.

After several months, if the practitioner remains unhappy with their compensation and continues to seek an increase, the administrator can call their bluff and encourage the practitioner to seek employment elsewhere with this request: ask if the compensation offered by the other organization assumes a fourday-workweek (a perk that the practitioner has been enjoying thus far) or a five-day-workweek. The four-day-workweek, much like the dead-end promotion, has been a trap set by the administrator and the organization, knowing that the practitioner would grow so accustomed to the lifestyle afforded by the perk that exit from the organization, even for higher compensation, is unlikely.

\section{Conclusion}

The responsibility in being mindful of messaging around social work practice and compensation falls upon BSW educators working with prospective social workers who are impressionable and generally new to the field. Prospective social workers who are led to believe that there is 'no money in social work,' are likely to find 'no money in social work.' 
There is no claim being made that social workers and nurses should be similarly compensated. Given the differences in working conditions, education, etc., the difference in compensation between social workers and nurses is well justified. However, the difference in median compensation being just $\$ 5,289$ in the early 2000 's to being $\$ 22,020$ in 2017 , with social workers now having less buying power now than they did before $21.4 \%$ growth in median salary against prices being $38.41 \%$ higher due to US inflation rate between 2001 and 2017 being 2.05\% per year), suggests that the field of social work is undervalued when in fact it is projected to grow 16\% from 2016 to 2026, which is 9\% higher than the projected growth for all occupations combined $[3,4]$.

Social work is a growing profession, but with growth come growing pains. Practitioners should stay aware of tactics potentially used against them to keep them where they are. It should be noted that most administrators and organizations welcome professional and compensatory development and growth over time, but many may not. It remains a fact that the top earner of almost every social work organization is not someone who has much social work experience, a trend that should shift in favor of social workers over the coming years and decades, mirroring the nursing profession. It should also be emphasized that compensation isn't confined to salaries alone. Practitioners should consistently negotiate their health, vision and dental insurance, vacation and sick days, memberships, professional development and organization-specific perks in addition to their salaries, not just at the start of their careers, but throughout their careers, at minimum on a yearly basis. Social work is a legitimate profession of advocacy, starting with the advocacy of self.

\section{References}

1. Linsley J (2003) Social Work Salaries: Keeping up with the Times. The New Social Worker 10(1).

2. Spratley E, Johnson A, Sochalski J, Fristz M, Spencer W (2001) The Registered Nurse Population, March 2000. Findings from the National Sample Survey of Registered Nurses. USA.

3. U.S. Department of Labor, Bureau of Labor Statistics (2019) Occupational outlook handbook, Registered Nurses. USA.

4. U.S. Department of Labor, Bureau of Labor Statistics (2019) Occupational outlook handbook, Social Workers. USA.

5. Guidestar (2019) The Financial Health of the United States Nonprofit Sector: Facts and Observations. USA.

6. Noe RA, Hollenbech JR, Gerhart B, Wright PM (2017) Human resource management: Gaining a competitive advantage. New York, NY: McGrawHill Education. USA.

7. USA Official Inflation Data (2019) 2001 dollars in 2017, Alioth Finance USA

Your next submission with Juniper Publishers will reach you the below assets 